\title{
Ionic liquids in the synthesis of high-performance fluorinated polyamides with backbones containing derivatives of imidazole and carbazole rings
}

\author{
Mousa Ghaemy, Marjan Hassanzadeh, Seyed Mojtaba Amini Nasab and Mehdi Taghavi
}

A series of new organosoluble poly(amide-ether-imidazole)s with different functional groups, such as flexible ether linkages, substituted imidazole and carbazole rings, and electron withdrawing $\mathrm{CF}_{3}$ groups, were synthesized from a new diamine and various dicarboxylic acids using two methods: (1) direct polycondensation with triphenyl phosphite (TPP) as an activating agent, $\mathrm{N}$-methyl-2-pyrrolidone (NMP), pyridine (Py) and $\mathrm{LiCl}$; and (2) direct polycondensation using ionic liquids (ILs) and TPP without Py, LiCl or NMP. Room temperature ILs containing anions such as $\mathrm{Br}^{-}, \mathrm{BF}^{-}{ }_{4}$ and $\mathrm{PF}^{-}{ }_{6}$ with symmetrical 1,3-dialkylimidazolium cations were prepared and used as polycondensation media. The polymers were obtained with good yields in ILs with moderate viscosities $\left(0.34-0.62 \mathrm{dlg}^{-1}\right)$ in a shorter reaction time $(2.5 \mathrm{vs} 12 \mathrm{~h})$ than in NMP. All of the polymers were amorphous in nature and showed excellent solubility in amide-type polar aprotic solvents. They showed good thermal stability with glass transition temperatures $\left(T_{\mathrm{g}}\right)$ between 162 and $303{ }^{\circ} \mathrm{C}$ and $10 \%$ weight loss temperatures of 388 and $421{ }^{\circ} \mathrm{C}$ in $\mathrm{O}_{2}$ and $\mathrm{N}_{2}$ atmospheres, respectively. These polymers showed blue fluorescence emission upon irradiation with ultraviolet light and are candidates for applications in electroluminescent devices.

Polymer Journal (2013) 45, 622-630; doi:10.1038/pj.2012.217; published online 23 January 2013

Keywords: fluorinated polymers; high-performance polymers; ionic liquids; polyamides; thermal stability

\section{INTRODUCTION}

Room temperature ionic liquids (ILs) have attracted extensive interest in recent years as environmentally benign solvents because of their favorable properties, such as reusability, negligible vapor pressure, thermal and chemical stability, non-volatility and non-flammability. In addition, their moderate polarity due to their ionic nature makes them able to dissolve organic, inorganic, organometallic and high-molecular-weight compounds, leading to their application in a variety of reactions as solvents and/or catalysts. ${ }^{1-4}$ ILs also attracted the attention of polymer chemists in recent years, and various polycondensation processes were successfully accomplished in ionic media as well. ${ }^{5-10}$ Reports have indicated that the reaction of different diamines with diacid chlorides in ILs resulted in the formation of high-molecular-weight polyamides (PAs). ${ }^{5,6}$

PAs are high-performance polymeric materials characterized by thermo-oxidative stability, good mechanical properties and outstanding solvent resistance. ${ }^{11-14}$ However, these polymers usually exhibit a limited solubility and high melting temperatures, decreasing their processability and restricting further applications. Therefore, researchers have been focused on the development of structurally modified aromatic PAs with increased solubility and better processability. ${ }^{15-17}$ One of the approaches that has been successful is the introduction of bulky pendants into the polymer backbone. ${ }^{18-20}$ Imidazole and carbazole rings and their derivatives have been incorporated into polymeric frameworks to improve the solubility of the polymers, ${ }^{21-26}$ and these groups have also been suggested as promising photoconductive and photorefractive materials. ${ }^{27-31}$ Carbazole units can also be easily functionalized with a variety of functional groups at the $(3,6),(2,7)$ or $N$-positions, and then covalently linked into polymeric systems. Although polymers with these functional units have been studied, difficulties in their introduction to high-performance polymers with respect to thermal, solubility and photophysical properties have not been overcome. ${ }^{32-34}$

This study reports the synthesis of a series of high-performance PAs based on a new aromatic diamine in ILs. Polar side groups such as $\mathrm{CF}_{3}$ and bulky phenyl groups along the polymer backbones were expected to give rise to restricted segmental mobility, leading overall to a high glass transition temperature $\left(T_{\mathrm{g}}\right)$ and an enhancement in solubility. The PAs were also expected to exhibit increased thermal stability because of the higher C-F bond strength. Because of the chromophore-substituted imidazole and carbazole rings in their backbones, these polymers were also expected to possess photophysical properties. 


\section{EXPERIMENTAL PROCEDURE}

Materials

All chemicals were purchased from Fluka and Merck Chemical (Darmstadt, Germany) through a local agency and were used as received without further purification. $\mathrm{N}$-methyl-2-pyrrolidone (NMP), $\mathrm{N}, \mathrm{N}$-dimethylacetamide and $\mathrm{Py}$ were purified by distillation under reduced pressure over calcium hydride and stored over $4 \AA$ molecular sieves.

\section{IL synthesis}

All room temperature ILs were prepared using procedures reported in the literature. ${ }^{10,35}$ Table 1 reports the structure of the ILs prepared here, all of which were highly viscous liquids at room temperature.

Table 1 The influence of IL cation and anion upon yield and inherent viscosity $\left(\eta_{\text {inh }}\right)$ of PAEI 1 and PAEI5

\begin{tabular}{|c|c|c|c|c|}
\hline Polymer & IL structure & IL & Yield (\%) & $\eta_{i n h}{ }^{a}$ \\
\hline PAEI1 & & {$\left[1,3\right.$-Isopropy| $\left.{ }_{2} \mathrm{im}\right] \mathrm{Br}$} & 82 & 0.50 \\
\hline PAEI5 & & & 85 & 0.34 \\
\hline PAEI1 & & {$\left[1,3-\right.$ Propyl $_{2}$ im] Br } & 90 & 0.62 \\
\hline PAEI5 & & & 92 & 0.37 \\
\hline PAEI1 & & {$\left[1,3-\right.$ Butyl $\left._{2} \mathrm{im}\right] \mathrm{Br}$} & 79 & 0.54 \\
\hline PAEI5 & & & 82 & 0.33 \\
\hline PAEI1 & & {$\left[1,3-\right.$ Pentyl $_{2}$ im $] \mathrm{Br}$} & 71 & 0.52 \\
\hline PAEI5 & & & 79 & 0.32 \\
\hline PAEI1 & & {$\left[1,3-\mathrm{Hexyl}_{2} \mathrm{im}\right] \mathrm{Br}$} & 79 & 0.44 \\
\hline PAEI5 & & & 81 & 0.34 \\
\hline PAEI1 & & {$\left[1,3-\mathrm{Heptyl}_{2} \mathrm{im}\right] \mathrm{Br}$} & 91 & 0.40 \\
\hline PAEI5 & & & 89 & 0.34 \\
\hline PAEI 1 & & {$\left[1,3-\right.$ Butyl $_{2} \mathrm{im} \mathrm{BF}_{4}$} & 68 & 0.39 \\
\hline PAEI5 & & & 71 & 0.33 \\
\hline PAEI1 & & {$\left[1,3-\right.$ Butyl $_{2} \mathrm{im} \mathrm{PF}_{6}$} & 64 & 0.33 \\
\hline PAEI5 & & & 70 & 0.28 \\
\hline
\end{tabular}

Abbreviations: $\eta_{\text {inh, }}$, inherent viscosity; IL, ionic liquid; NMP, $N$-methyl-2-pyrrolidone; PAEI, poly(amide-ether-imidazole).

aMeasured at a concentration of $0.5 \mathrm{~g} \mathrm{dl}^{-1}$ in NMP at $25^{\circ} \mathrm{C}$

\section{Monomer synthesis}

Scheme 1 outlines the synthetic method leading to the targeted diamine.

Synthesis of $4,4^{\prime}$-dihydroxybenzyl (1). Into a $100-\mathrm{ml}$ round-bottomed, twonecked flask equipped with a magnetic stir bar and a reflux condenser, $4,4^{\prime}$-dimethoxybenzil $(2 \mathrm{~g}, 0.0075 \mathrm{mmol})$, aqueous $\mathrm{HBr}(15 \mathrm{ml}, 48 \%)$ and glacial acetic acid $(15 \mathrm{ml})$ were placed. The reaction mixture was refluxed for $24 \mathrm{~h}$, and after cooling to room temperature, it was poured into $100 \mathrm{ml}$ of water. Ethyl acetate was added to the mixture to obtain two phases, and the organic phase containing the product was separated and dried over magnesium sulfate for $12 \mathrm{~h}$. The solvent was removed under reduced pressure and the yellow precipitate was washed thoroughly with water and then dried in a vacuum oven at $80^{\circ} \mathrm{C}$. Yield: $94 \%(1.7 \mathrm{~g})$, and melting point (m.p.): $229-231{ }^{\circ} \mathrm{C}$. Fourier transform infrared spectroscopy (FT-IR) $(\mathrm{KBr})$ at $\mathrm{cm}^{-1}$ : 3400 (OH phenol); 3045 (C-H aromatic); $1646(\mathrm{C}=\mathrm{O}) ; 1576(\mathrm{C}=\mathrm{C})$; and 1223 (C-O). Proton nuclear magnetic resonance spectroscopy ( $\left.{ }^{1} \mathrm{H}-\mathrm{NMR}\right)$ ( $400 \mathrm{MHz}$, dimethyl sulfoxide (DMSO) $-d_{6}$ ) $): \delta 6.91-6.95(\mathrm{~d}, 4 \mathrm{H}, J=8.0 \mathrm{~Hz}$ ), $7.73-7.77(\mathrm{~d}, 4 \mathrm{H}, J=8.0 \mathrm{~Hz})$ and $10.84(\mathrm{~s}, 2 \mathrm{H})$.

Synthesis of 1,2-bis(4-(4-nitro-2-(trifluoromethyl)phenoxy)phenyl)ethane-1,2dione (2). Into a $100-\mathrm{ml}$ round-bottomed, two-necked flask equipped with a magnetic stirrer bar and a reflux condenser, 4,4'-dihydroxybenzyl $(1.21 \mathrm{~g}$, $0.005 \mathrm{~mol}$ ) and 1-chloro-4-nitro-2-(trifluoromethyl) benzene $(2.25 \mathrm{~g}, 0.01 \mathrm{~mol})$

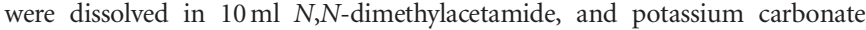
$(1.38 \mathrm{~g}, 0.01 \mathrm{~mol})$ was added to the solution. After $30 \mathrm{~min}$ of stirring at room temperature, the mixture was heated at $110^{\circ} \mathrm{C}$ for $6 \mathrm{~h}$. The mixture was poured into $100 \mathrm{ml}$ water and the yellow precipitate was collected by filtration and dried in a vacuum oven at $80^{\circ} \mathrm{C}$. Yield: $93 \%(2.9 \mathrm{~g})$, and m.p.: $157-160^{\circ} \mathrm{C}$.

FT-IR $(\mathrm{KBr})$ at $\mathrm{cm}^{-1}$ : 3045 (aromatic $\left.\mathrm{C}-\mathrm{H}\right) ; 1621(\mathrm{C}=\mathrm{O}), 1482(\mathrm{C}=\mathrm{C})$; 1534, $1353\left(\mathrm{NO}_{2}\right)$; and 1268 (C-O stretching). ${ }^{1} \mathrm{H}-\mathrm{NMR}(400 \mathrm{MHz}, \mathrm{DMSO}-$ $\left.d_{6}\right): \delta 7.41(\mathrm{~d}, 4 \mathrm{H}, \operatorname{Ar}-\mathrm{H}, J=8.0 \mathrm{~Hz}), 7.46(\mathrm{~d}, 2 \mathrm{H}, \operatorname{Ar}-\mathrm{H}, J=8.0 \mathrm{~Hz}), 8.08$ $(\mathrm{d}, 4 \mathrm{H}, \mathrm{Ar}-\mathrm{H}, J=8.0 \mathrm{~Hz}), 8.54(\mathrm{dd}, 2 \mathrm{H}, \mathrm{Ar}-\mathrm{H}, J=8.0 \mathrm{~Hz})$ and $8.57(\mathrm{~d}, 2 \mathrm{H}$, Ar- $\mathrm{H}, J=2.8 \mathrm{~Hz})$

2-(4,5-bis(4-(4-nitro-2-(trifluoromethyl)phenoxy)phenyl)-1H-imidazol-2-yl)-9ethyl-carbazole (3). Into a 100-ml round-bottomed, two-necked flask equipped with a condenser, a magnetic stir bar and a nitrogen gas inlet tube, a mixture of 9-ethyl-carbazole-2-carbaldehyde $(1.11 \mathrm{~g}, 0.005 \mathrm{~mol})$, Compound $2(3.1 \mathrm{~g}$, $0.005 \mathrm{~mol})$, ammonium acetate $(2.7 \mathrm{~g}, 0.035 \mathrm{~mol})$ and glacial acetic acid $(25 \mathrm{ml})$ was refluxed for $14 \mathrm{~h}$. Upon cooling, the yellow precipitate was collected by filtration, washed with a mixture of $\mathrm{C}_{2} \mathrm{H}_{5} \mathrm{OH} / \mathrm{H}_{2} \mathrm{O}\left(50 / 50\left(\mathrm{v} \mathrm{v}^{-1}\right)\right)$ and dried in a vacuum oven at $80{ }^{\circ} \mathrm{C}$. Yield: $91 \%$ (3.75 g), and m.p.: $170-173^{\circ} \mathrm{C}$.

FT-IR ( $\mathrm{KBr}$ ) at cm ${ }^{-1}$ : 3473 (NH, imidazole ring); 3062 (aromatic C-H); 2904 (aliphatic C-H); $1612(\mathrm{C}=\mathrm{N}) ; 1586 \quad(\mathrm{C}=\mathrm{C}), 1546,1349 \quad\left(\mathrm{NO}_{2}\right)$; $1278(\mathrm{C}-\mathrm{N})$, and $1237(\mathrm{C}-\mathrm{O}-\mathrm{C}) .{ }^{1} \mathrm{H}-\mathrm{NMR}\left(400 \mathrm{MHz}, \mathrm{DMSO}-d_{6}\right): \delta 1.36$ $\left(\mathrm{t}, 3 \mathrm{H}, \mathrm{CH}_{3}\right), 4.50\left(\mathrm{q}, 2 \mathrm{H}, \mathrm{CH}_{2}\right), 7.19(\mathrm{~d}, 2 \mathrm{H}, \mathrm{Ar}-\mathrm{H}, \mathrm{J}=8.0 \mathrm{~Hz}), 7.23(\mathrm{~d}, 2 \mathrm{H}$, Ar- $\mathrm{H}, J=8.0 \mathrm{~Hz}), 7.27(\mathrm{t}, 1 \mathrm{H}, \mathrm{Ar}-\mathrm{H}, J=8.0 \mathrm{~Hz}), 7.36(\mathrm{~d}, 2 \mathrm{H}, \mathrm{Ar}-\mathrm{H}, J=8.0$ $\mathrm{Hz}), 7.50(\mathrm{t}, 1 \mathrm{H}, \mathrm{Ar}-\mathrm{H}, J=8.0 \mathrm{~Hz}), 7.66(\mathrm{~d}, 2 \mathrm{H}, \mathrm{Ar}-\mathrm{H}, J=8.0 \mathrm{~Hz}), 7.73(\mathrm{~d}$, $2 \mathrm{H}, \mathrm{Ar}-\mathrm{H}, J=8.0 \mathrm{~Hz}), 7.77(\mathrm{~d}, 2 \mathrm{H}, \mathrm{Ar}-\mathrm{H}, J=8.0 \mathrm{~Hz}), 8.19(\mathrm{~d}, 1 \mathrm{H}, \mathrm{Ar}-\mathrm{H}$,

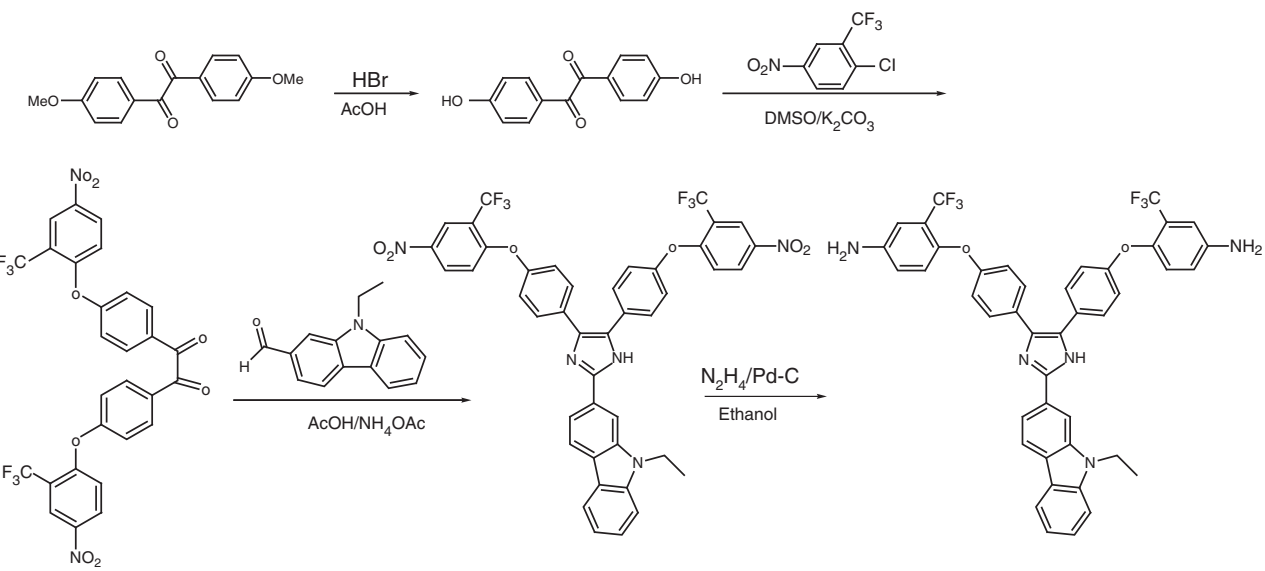

Scheme 1 Synthesis of the target diamine. 
$J=8.0 \mathrm{~Hz}), 8.24(\mathrm{dd}, 1 \mathrm{H}, \mathrm{Ar}-\mathrm{H}, J=8.0 \mathrm{~Hz}), 8.48$ (d, $2 \mathrm{H}, \mathrm{Ar}-\mathrm{H}, J=2.8 \mathrm{~Hz}$ ), $8.55(\mathrm{dd}, 2 \mathrm{H}, \mathrm{Ar}-\mathrm{H}, J=8.0 \mathrm{~Hz}), 8.87(\mathrm{~d}, 1 \mathrm{H}, \mathrm{Ar}-\mathrm{H}, J=1.6 \mathrm{~Hz})$ and 12.57 (s, $1 \mathrm{H}, \mathrm{N}-\mathrm{H}$ imidazole ring). Anal. Calcd. for $\mathrm{C}_{43} \mathrm{H}_{27} \mathrm{~N}_{5} \mathrm{O}_{6} \mathrm{~F}_{6}\left(823 \mathrm{~g} \mathrm{~mol}^{-1}\right)$ : C, $62.69 \%$;, $3.28 \%$; and N, 8.50\%. Found: C, 62.66\%; H, 3.30\%; and N, $8.50 \%$. 4,4'-(4,4'-(2-(9-ethyl-carbazol-2-yl)-1H-imidazole-4,5-diyl)bis(4,1-phenylene))bis(oxy) bis(3-(trifluoromethyl)aniline) (4). Into a 100-ml round-bottomed, two-necked flask equipped with a magnetic stir bar, a mixture of Compound 3 $(4.10 \mathrm{~g}, 0.005 \mathrm{~mol})$ and $\mathrm{Pd} / \mathrm{C}(0.1 \mathrm{~g}, 10 \%)$ was dispersed in $50 \mathrm{~m}$ ethanol. The suspension was heated to reflux, and then $6 \mathrm{ml}$ hydrazine monohydrate was slowly added to the mixture. After a further $8 \mathrm{~h}$ of reflux, the solution was filtered while hot to remove $\mathrm{Pd} / \mathrm{C}$, and then the filtrate was cooled to precipitate white crystals. The product was collected by filtration and dried in a vacuum oven at $80^{\circ} \mathrm{C}$. Yield: $86 \%(3.26 \mathrm{~g})$, and m. p.: $155-157^{\circ} \mathrm{C}$.

FT-IR (KBr) at cm ${ }^{-1}$ : 3478, $3373\left(\mathrm{NH}_{2}\right) ; 3462(\mathrm{~N}-\mathrm{H}$ imidazole ring); 3051 (C-H aromatic); 2912 (aliphatic C-H); $1628(\mathrm{C}=\mathrm{N}) ; 1597(\mathrm{C}=\mathrm{C}) ; 1286$ $(\mathrm{C}-\mathrm{N})$; and $1214(\mathrm{C}-\mathrm{O}-\mathrm{C}) .{ }^{1} \mathrm{H}-\mathrm{NMR}\left(400 \mathrm{MHz}, \mathrm{DMSO}-d_{6}\right): \delta 1.35(\mathrm{t}, 3 \mathrm{H}$, $\left.\mathrm{CH}_{3}\right), 4.47\left(\mathrm{q}, 2 \mathrm{H}, \mathrm{CH}_{2}\right), 5.47\left(\mathrm{~s}, 2 \mathrm{H}, \mathrm{NH}_{2}\right), 5.52\left(\mathrm{~s}, 2 \mathrm{H}, \mathrm{NH}_{2}\right), 6.82-6.99(\mathrm{~m}$, $10 \mathrm{H}, \mathrm{Ar}-\mathrm{H}), 7.25(\mathrm{t}, 1 \mathrm{H}, \mathrm{Ar}-\mathrm{H}), 7.47(\mathrm{t}, 1 \mathrm{H}, \mathrm{Ar}-\mathrm{H}), 7.49(\mathrm{~d}, 2 \mathrm{H}, \mathrm{Ar}-\mathrm{H}$, $J=8.0 \mathrm{~Hz}), 7.56(\mathrm{~d}, 2 \mathrm{H}, \mathrm{Ar}-\mathrm{H}, J=8.0 \mathrm{~Hz}), 7.64(\mathrm{~d}, 1 \mathrm{H}, \mathrm{Ar}-\mathrm{H}, J=8.0 \mathrm{~Hz}), 7.70$ (d, $1 \mathrm{H}, \mathrm{Ar}-\mathrm{H}, J=8.0 \mathrm{~Hz}), 8.15(\mathrm{~d}, 1 \mathrm{H}, \mathrm{Ar}-\mathrm{H}, J=8.0 \mathrm{~Hz}), 8.21(\mathrm{dd}, 1 \mathrm{H}, \mathrm{Ar}-\mathrm{H}$, $J=8.4 \mathrm{~Hz}), 8.82(\mathrm{~d}, 1 \mathrm{H}, \mathrm{Ar}-\mathrm{H}, J=1.6 \mathrm{~Hz})$ and $12.51(\mathrm{~s}, 1 \mathrm{H}, \mathrm{N}-\mathrm{H}$ imidazole ring). Carbon-13 nuclear magnetic resonance $\left({ }^{13} \mathrm{C}-\mathrm{NMR}\right)(100 \mathrm{MHz}$, DMSO$\left.d_{6}, \delta\right): 1$ (14.23), 2 (37.56), 3 (109.71), 4 (109.83), 5 (111.16), 6 (115.51), 7 (115.97), 8 (116.36, 117.00, 117.08 and 117.58), 9 (119.09), 10 (119.59), 11 (120.71), 12 (121.68, 121.98, 122.09 and 122.26), 13 (122.70, 125.41, 125.42 and 128.63), 14 (122.73), 15 (123.57), 16 (123.98), 17 (124.55), 18 (126.03), 19 (126.49), 20 (127.04), 21 (128.83), 22 (130.37), 23 (130.46), 24 (131.90), 25 (136.42), 26 (139.92), 27 (140.49), 28 (142.32), 29 (142.96), 30 (146.19, 146.54 and 146.90), 31 (157.47) and 32 (158.49). Distortionless Enhancement by Polarization Transfer (DEPT) technique (100 MHz, DMSO- $\left.d_{6}, \delta\right): 1$ (14.22), 2 (37.56), 3 (109.71), 4 (109.84), 5 (111.15), 7 (115.97), 8 (116.35, 116.99, 117.08 and 117.58), 9 (119.09), 10 (119.59), 11 (120.71), 15 (123.58), 16 (123.99), 19 (126.49), 21 (128.83), 22 (130.37) and 24 (131.90).

Anal. Calcd. for $\mathrm{C}_{43} \mathrm{H}_{31} \mathrm{~N}_{5} \mathrm{O}_{2} \mathrm{~F}_{6}\left(763 \mathrm{~g} \mathrm{~mol}^{-1}\right)$ : C, $67.62 \%$; $\mathrm{H}, 4.06 \%$; and $\mathrm{N}$, 9.17\%. Found: C, $67.59 \%$; H, 4.10\%; and N, 9.16\%.

\section{Polymer synthesis}

Method I. direct polycondensation using TPP/NMP/Py/LiCl. The following general procedure was used for the preparation of poly(amide-ether-imidazole)s (PAEIs) from the diamine and various aliphatic and aromatic dicarboxylic acids. In a three-necked, round-bottomed flask equipped with a condenser, a mechanical stirrer and a nitrogen gas inlet tube, diamine 4 $(1 \mathrm{mmol}, 0.763 \mathrm{~g})$, a dicarboxylic acid $(1 \mathrm{mmol})$ and $\mathrm{LiCl}(0.30 \mathrm{~g})$ were dissolved in a mixture of Py $(1 \mathrm{ml})$, triphenyl phosphite (TPP) $(1.20 \mathrm{mmol})$ and NMP $(5 \mathrm{ml})$. The mixture was heated at $120^{\circ} \mathrm{C}$ under a dry $\mathrm{N}_{2}$ atmosphere for $12 \mathrm{~h}$ with stirring. The reaction mixture was then cooled to room temperature and the resulting polymers were precipitated in $200 \mathrm{ml}$ methanol. The precipitate was filtered and washed with hot water, and was then further purified by washing with refluxing methanol for $24 \mathrm{~h}$ in a Soxhlet apparatus to remove the low-molecular-weight oligomes. The inherent viscosities of the polymers were measured at concentrations of $0.5 \mathrm{~g} \mathrm{dl}^{-1}$ in NMP at $25^{\circ} \mathrm{C}$, and were in the range of $0.34-0.62 \mathrm{dlg}^{-1}$.

Method II. direct polycondensation using TPP/ILs. The following general procedure, as illustrated in Scheme 2, was used for the preparation of PAEIs from the diamine and various aliphatic and aromatic dicarboxylic acids.

Into a 10-ml three-necked, round-bottomed flask fitted with a water-cooled condenser, a mechanical stirrer and a nitrogen gas inlet tube, a mixture of diamine 4 ( $1 \mathrm{mmol}, 0.763 \mathrm{~g})$, terphthalic acid ( $1 \mathrm{mmol}, 0.166 \mathrm{~g}), 1,3$-dipropyl imidazolium bromide $\left(\left[1,3-(\mathrm{pr})_{2} \mathrm{im}\right] \mathrm{Br}\right)(0.70 \mathrm{~g})$ and $\left.\mathrm{TPP}(1.29 \mathrm{mmol})\right)$ was introduced. The mixture was heated at $110^{\circ} \mathrm{C}$ for $2.5 \mathrm{~h}$. As the reaction proceeded, the solution became viscous. The reaction mixture was then cooled to room temperature, and the resulting polymers were precipitated in $100 \mathrm{ml}$ methanol. The precipitate was filtered and washed with hot water, and was then further purified by washing with refluxing methanol for $24 \mathrm{~h}$ in a Soxhlet apparatus to remove the low-molecular-weight oligomers. The inherent viscosity $\left(\eta_{\text {inh }}\right)$ of the resulting PAEIs was between 0.34 and $0.62 \mathrm{dlg}^{-1}$, measured at concentrations of $0.5 \mathrm{~g} \mathrm{dl}^{-1}$ in NMP at $25^{\circ} \mathrm{C}$. All other PAEIs were prepared using the above procedure.

PAEI1. Yield $=90 \%$, and $\eta_{\text {inh }}\left(\mathrm{dlg}^{-1}\right)=0.62$. FT-IR $(\mathrm{KBr})$ at $\mathrm{cm}^{-1}: 3432$, $3202(\mathrm{~N}-\mathrm{H}) ; 3052$ (aromatic C-H); 2862 (aliphatic C-H); $1663(\mathrm{C}=\mathrm{O}), 1642$ $(\mathrm{C}=\mathrm{N})$; and $1266(\mathrm{C}-\mathrm{N}) .{ }^{1} \mathrm{H}-\mathrm{NMR}\left(400 \mathrm{MHz}, \mathrm{DMSO}-d_{6}\right): \delta 1.37(\mathrm{t}, 3 \mathrm{H}$, $\left.\mathrm{CH}_{3}\right), 4.50$ (q, 2H, $\left.\mathrm{CH}_{2}\right), 7.08-7.71(\mathrm{~m}, 15 \mathrm{H}, \mathrm{Ar}-\mathrm{H}), 8.17-8.62$ (m, 9H, Ar-H), $8.91(\mathrm{~s}, 1 \mathrm{H}, \mathrm{Ar}-\mathrm{H}), 10.76(\mathrm{~s}, 2 \mathrm{H}, \mathrm{N}-\mathrm{H}$ amide $)$ and $12.63(\mathrm{~s}, 1 \mathrm{H}, \mathrm{N}-\mathrm{H}$, imidazole ring). Anal. Calcd. for $\mathrm{C}_{51} \mathrm{H}_{33} \mathrm{~N}_{5} \mathrm{O}_{4} \mathrm{~F}_{6}\left(893 \mathrm{~g} \mathrm{~mol}^{-1}\right)$ : $\mathrm{C}, 68.53 \%$; $\mathrm{H}$, 3.69\%; and N, 7.83\%. Found: C, 68.49\%; H, 3.78\%; and N, 7.81\%.

PAEI2. Yield $=87 \%$, and $\eta_{\text {inh }}\left(\mathrm{dlg}^{-1}\right)=0.51$. FT-IR $(\mathrm{KBr})$ at $\mathrm{cm}^{-1}: 3428$, $3198(\mathrm{~N}-\mathrm{H}) ; 3046$ (aromatic C-H); 2867 (aliphatic C-H); $1665(\mathrm{C}=\mathrm{O}), 1642$ $(\mathrm{C}=\mathrm{N}) ; 1264(\mathrm{C}-\mathrm{N}) .{ }^{1} \mathrm{H}-\mathrm{NMR}\left(400 \mathrm{MHz}, \mathrm{DMSO}-d_{6}\right): \delta 1.36\left(\mathrm{t}, 3 \mathrm{H}, \mathrm{CH}_{3}\right)$, $4.48\left(\mathrm{q}, 2 \mathrm{H}, \mathrm{CH}_{2}\right), 7.06-7.25(\mathrm{~m}, 7 \mathrm{H}, \mathrm{Ar}-\mathrm{H}), 7.50-7.64(\mathrm{~m}, 8 \mathrm{H}, \mathrm{Ar}-\mathrm{H})$, 8.16-8.34 (m, 8H, Ar-H), 8.58 (d, 1H, Ar-H), 8.85 (s, 1H, Ar-H), 10.74 (s, 2H, $\mathrm{N}-\mathrm{H}$ amide) and $12.61(\mathrm{~s}, 1 \mathrm{H}, \mathrm{N}-\mathrm{H}$, imidazole ring). Anal. Calcd. for $\mathrm{C}_{51} \mathrm{H}_{33} \mathrm{~N}_{5} \mathrm{O}_{4} \mathrm{~F}_{6}\left(893 \mathrm{~g} \mathrm{~mol}^{-1}\right)$ : C, $68.53 \%$; H, 3.69\%; and N, 7.83\%. Found: C, $68.50 \% ; \mathrm{H}, 3.73 \%$; and $\mathrm{N}, 7.82 \%$.

PAEI3. Yield $=85 \%$, and $\eta_{\text {inh }}\left(\mathrm{dlg}^{-1}\right)=0.39$. FT-IR $(\mathrm{KBr})$ at $\mathrm{cm}^{-1}: 3417$, $3187(\mathrm{~N}-\mathrm{H}) ; 3041$ (aromatic C-H); 2861 (aliphatic C-H); $1647(\mathrm{C}=\mathrm{O}) ; 1638$ $(\mathrm{C}=\mathrm{N}) ; 1262(\mathrm{C}-\mathrm{N}) .{ }^{1} \mathrm{H}-\mathrm{NMR}\left(400 \mathrm{MHz}, \mathrm{DMSO}-d_{6}\right): \delta 1.39\left(\mathrm{t}, 3 \mathrm{H}, \mathrm{CH}_{3}\right)$, 4.55 (q, 2H, $\mathrm{CH}_{2}$ ), 7.12-7.77 (m, 14H, Ar-H), 8.20-8.68 (m, 9H, Ar-H), 8.96 (s, 1H, Ar-H), $10.80(\mathrm{~s}, 2 \mathrm{H}, \mathrm{N}-\mathrm{H}$ amide) and $12.69(\mathrm{~s}, 1 \mathrm{H}, \mathrm{N}-\mathrm{H}$, imidazole ring). Anal. Calcd. for $\mathrm{C}_{50} \mathrm{H}_{32} \mathrm{~N}_{6} \mathrm{O}_{4} \mathrm{~F}_{6}\left(894 \mathrm{~g}^{-1} \mathrm{~mol}^{-1}\right)$ : C, $67.11 \%$; $\mathrm{H}, 3.57 \%$; and N, 9.39\%. Found: C, 67.09\%; H, 3.60\%; and N, 9.36\%.

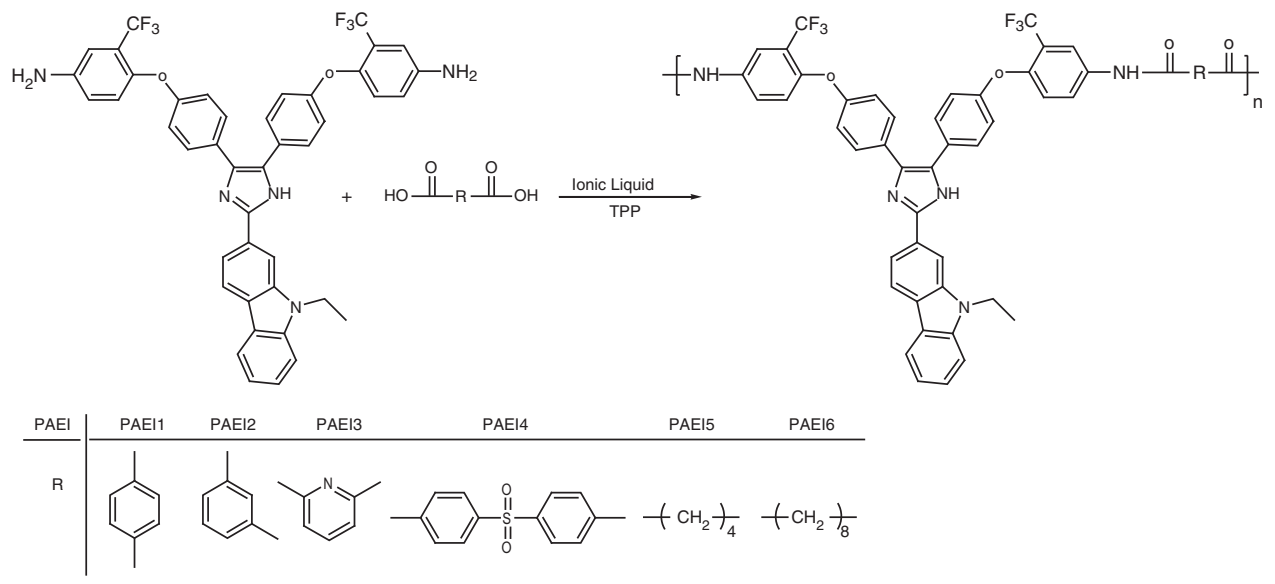

Scheme 2 Polycondensation reactions of the diamine with different dicarboxylic acids. 
PAEI4. Yield $=91 \%$, and $\eta_{\text {inh }}\left(\mathrm{dlg}^{-1}\right)=0.53$. FTIR $(\mathrm{KBr})$ at $\mathrm{cm}^{-1}: 3418,3177$ $(\mathrm{N}-\mathrm{H}) ; 3046$ (aromatic C-H); 2879 (aliphatic $\mathrm{C}-\mathrm{H}) ; 1642(\mathrm{C}=\mathrm{O}) ; 1637$ $(\mathrm{C}=\mathrm{N})$; and $\left.1262(\mathrm{C}-\mathrm{N}) .{ }^{1} \mathrm{H}-\mathrm{NMR}\left(400 \mathrm{MHz}, \mathrm{DMSO}-d_{6}\right)\right): \delta 1.42(\mathrm{t}, 3 \mathrm{H}$, $\left.\mathrm{CH}_{3}\right), 4.56\left(\mathrm{q}, 2 \mathrm{H}, \mathrm{CH}_{2}\right), 7.16-7.79(\mathrm{~m}, 8 \mathrm{H}, \mathrm{Ar}-\mathrm{H}), 7.53-7.66(\mathrm{~m}, 8 \mathrm{H}, \mathrm{Ar}-\mathrm{H})$, 8.18-8.36 (m, 8H, Ar-H), $8.72(4 \mathrm{H}, \mathrm{Ar}-\mathrm{H}), 8.99$ (s, $1 \mathrm{H}, \mathrm{Ar}-\mathrm{H}), 10.84(\mathrm{~s}, 2 \mathrm{H}$, $\mathrm{N}-\mathrm{H}$ amide) and $12.71(\mathrm{~s}, 1 \mathrm{H}, \mathrm{N}-\mathrm{H}$, imidazole ring). Anal. Calcd. for $\mathrm{C}_{57} \mathrm{H}_{37} \mathrm{~N}_{5} \mathrm{O}_{6} \mathrm{~F}_{6}\left(1001 \mathrm{~g}^{-1} \mathrm{~mol}^{-1}\right)$ : C, 68.33\%; H, 3.69\%; and N, 6.99\%. Found: C, $68.30 \%$; H, 3.69\%; and N, 6.97\%.

PAEI5. Yield $=92 \%$, and $\eta_{\text {inh }}\left(\mathrm{dl} \mathrm{g}^{-1}\right)=0.37$. FTIR $(\mathrm{KBr})$ at $\mathrm{cm}^{-1}: 3455,3217$ $(\mathrm{N}-\mathrm{H}) ; 3061$ (aromatic C-H); 2845 (aliphatic $\mathrm{C}-\mathrm{H}) ; 1673(\mathrm{C}=\mathrm{O}) ; 1647$ $(\mathrm{C}=\mathrm{N})$; and $1267(\mathrm{C}-\mathrm{N}) .{ }^{1} \mathrm{H}-\mathrm{NMR}\left(400 \mathrm{MHz}, \mathrm{DMSO}-d_{6}\right): \delta 1.45(3 \mathrm{H}, \mathrm{CH})$, $1.57(4 \mathrm{H}, \mathrm{CH}), 2.34(4 \mathrm{H}, \mathrm{CH}), 4.52(2 \mathrm{H}, \mathrm{CH}), 6.93-7.39(\mathrm{~m}, 7 \mathrm{H}, \mathrm{Ar}-\mathrm{H})$, 7.55-8.31 (m, 13H, Ar-H), 9.13 (s, 1H, Ar-H), 10.37 (s, 2H, N-H amide) and $11.97\left(\mathrm{~s}, 1 \mathrm{H}, \quad \mathrm{N}-\mathrm{H}\right.$, imidazole ring). Anal. Calcd. for $\mathrm{C}_{49} \mathrm{H}_{37} \mathrm{~N}_{5} \mathrm{O}_{4} \mathrm{~F}_{6}$ $\left(873 \mathrm{~g} \mathrm{~mol}^{-1}\right)$ : C, $67.35 \% ; \mathrm{H}, 4.23 \%$; and N, $8.01 \%$. Found: C, $67.29 \% ; \mathrm{H}$, $4.34 \%$; and $\mathrm{N}, 8.00 \%$.

PAEI6. Yield $=95 \%$, and $\eta_{\text {inh }}\left(\mathrm{dl} \mathrm{g}^{-1}\right)=0.34$. FTIR $(\mathrm{KBr})$ at $\mathrm{cm}^{-1}: 3455,3217$ $(\mathrm{N}-\mathrm{H}) ; 3061$ (aromatic C-H); 2845 (aliphatic C-H); $1673(\mathrm{C}=\mathrm{O}) ; 1647$ $(\mathrm{C}=\mathrm{N})$; and $1267(\mathrm{C}-\mathrm{N}) .{ }^{1} \mathrm{H}-\mathrm{NMR}\left(400 \mathrm{MHz}, \mathrm{DMSO}-d_{6}\right): \delta \quad 1.29-1.35$ $(\mathrm{m}, 8 \mathrm{H}, \mathrm{CH}), 1.47(3 \mathrm{H}, \mathrm{CH}), 1.59(4 \mathrm{H}, \mathrm{CH}), 2.33(4 \mathrm{H}, \mathrm{CH}), 4.52(2 \mathrm{H}, \mathrm{CH})$, 6.91-7.31 (m, 7H, Ar-H), 7.55-7.88 (m, 9H, Ar-H), 8.18 (d, 2H, Ar-H), 8.27 (d, 2H, Ar-H), 9.05 (s, 1H, Ar-H), 10.34 (s, 2H, N-H amide) and 11.96 (s, $1 \mathrm{H}, \mathrm{N}-\mathrm{H}$, imidazole ring). Anal. Calcd. for $\mathrm{C}_{53} \mathrm{H}_{43} \mathrm{~N}_{5} \mathrm{O}_{4} \mathrm{~F}_{6}\left(927 \mathrm{~g}^{-1}\right.$ $\mathrm{mol}^{-1}$ ): C, $68.60 \%$; H, 4.63\%; and N, 7.55\%. Found: C, 68.58\%; H, 4.68\%; and $\mathrm{N}, 7.52 \%$.

\section{Characterization}

${ }^{1} \mathrm{H}-\mathrm{NMR}$ and ${ }^{13} \mathrm{C}$-NMR spectra were recorded on a $400 \mathrm{MHz}$ Bruker Avance DRX (Bruker, Karlsruhe, Germany) instrument using DMSO- $d_{6}$ as the solvent and tetramethyl silane as the internal standard. Proton resonances are designated as singlet (s), doublet (d) and multiplet (m). FTIR spectra (Bruker) were recorded on $\mathrm{KBr}$ pellets using a Bruker Tensor 27 spectrometer (Bruker) over the range of $400-4000 \mathrm{~cm}^{-1}$. Elemental analyses were performed by a CHN-600 Leco elemental analyzer (MI, USA). The melting point (uncorrected) was measured with a Barnstead Electrothermal engineering LTD 9200 apparatus (Southerland, UK). Inherent viscosities (at a concentration of $\left.0.5 \mathrm{~g}^{-1} \mathrm{dl}^{-1}\right)$ were measured with an Ubbelohde suspended-level viscometer (Schott-Gerate, Hofheim, Germany) at $25^{\circ} \mathrm{C}$ using NMP as the solvent. Quantitative solubility was determined using $0.05 \mathrm{~g}$ of the polymer in $0.5 \mathrm{ml}$ of solvent. Thermogravimetric analysis (TGA) was performed with a DuPont Instruments (TGA 951) analyzer (Wilmington, NC, USA) at a heating rate of $10^{\circ} \mathrm{Cmin}^{-1}$ under nitrogen atmosphere $\left(20 \mathrm{~cm}^{3} \mathrm{~min}^{-1}\right)$ over the temperature range of $30-650^{\circ} \mathrm{C}$. Differential scanning calorimetry (DSC) data were recorded on a Perkin-Elmer Pyris 6 DSC (Groningen, The Netherlands) under nitrogen atmosphere $\left(20 \mathrm{~cm}^{3} \mathrm{~min}^{-1}\right)$ at a heating rate of $10{ }^{\circ} \mathrm{Cmin}^{-1} . T_{\mathrm{g}}$ values were taken as the middle of the transition in heat capacity in the second heating scan after cooling from $350{ }^{\circ} \mathrm{C}$ at a rate of $20^{\circ} \mathrm{C} \mathrm{min}^{-1}$. Ultraviolet-visible and fluorescence emission spectra were recorded on Cecil 5503 (Cecil Instruments, Cambridge, UK) and PerkinElmer LS-3B spectrophotometers (Norwalk, CT, USA) (slit width $2 \mathrm{~nm}$ ), respectively, using a dilute polymer solution $\left(0.20 \mathrm{~g} \mathrm{dl}^{-1}\right)$ in DMSO. X-ray powder diffraction patterns were recorded by an X-ray diffractometer (GBC MMA Instrument, Wollongong, NSW, Australia) with a Be-filtered $\mathrm{Cu} \mathrm{K}$ source $(1.5418 \AA$ ) operating at $35.4 \mathrm{kV}$ and $28 \mathrm{~mA}$. The $2 \theta$ scanning range was set between $4^{\circ}$ and $50^{\circ}$ at a scan rate of $0.05^{\circ} \mathrm{s}^{-1}$.

\section{RESULTS AND DISCUSSION}

Synthesis and characterization of diamine (4)

A new diamine, 4,4'-(4,4'-(2-(9-ethyl-carbazol-2-yl)-1H-imidazole4,5-diyl)bis(4,1-phenylene))bis(oxy)bis(3-(trifluoromethyl)aniline), was synthesized according to the synthetic route shown in Scheme 1. Compound 1 was synthesized by the hydrolysis of 4,4'-dimethoxybenzil with aqueous $\mathrm{HBr}$ and glacial acetic acid. Compound 2 was synthesized by a nucleophilic aromatic substitution reaction of 4, 4'-dihydroxybenzyl with 2-chloro-5-nitrobenzotrifluoride. The reaction between Compound 2- and 9-ethyl-carbazole-2-carbaldehyde with an excess of ammonium acetate, a well known synthetic method for the preparation of an imidazole ring, was used to synthesize Compound $3 .^{36}$ The catalytic hydrogenation of the dinitro groups in Compound 3 into the corresponding diamine was accomplished using hydrazine hydrate in ethanol in the presence of a catalytic amount of $\mathrm{Pd} / \mathrm{C}$.

The purity of all compounds was checked by thin-layer chromatography using an ethylacetate $/ n$-hexane mixture. The structure of diamine 4 was confirmed by elemental analysis, FT-IR and ${ }^{1} \mathrm{H}$ - and

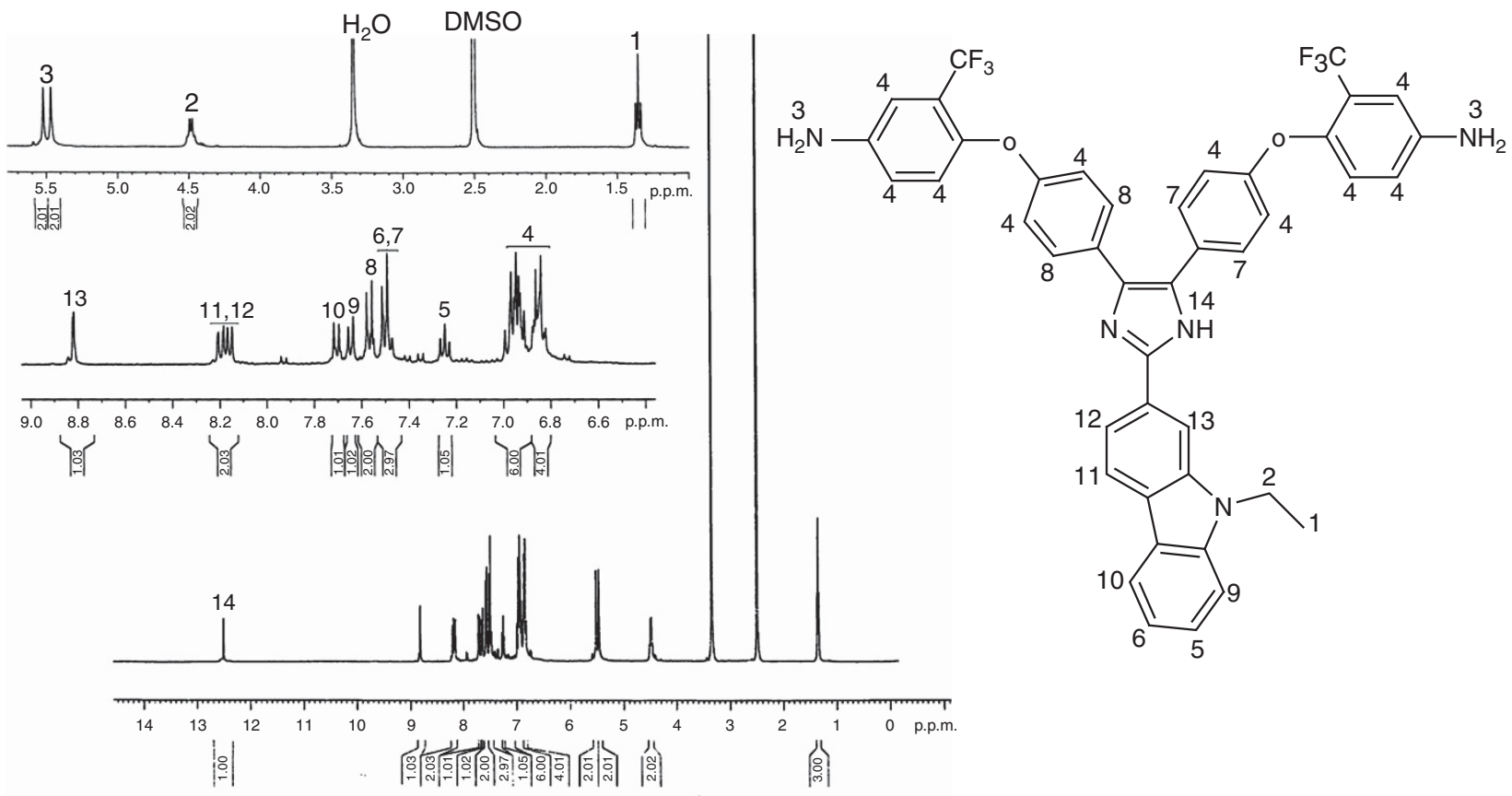

Figure 1 Proton nuclear magnetic resonance spectroscopy $\left({ }^{1} \mathrm{H}-\mathrm{NMR}\right)$ spectrum of diamine (4) in dimethyl sulfoxide (DMSO)- $d_{6}$. 

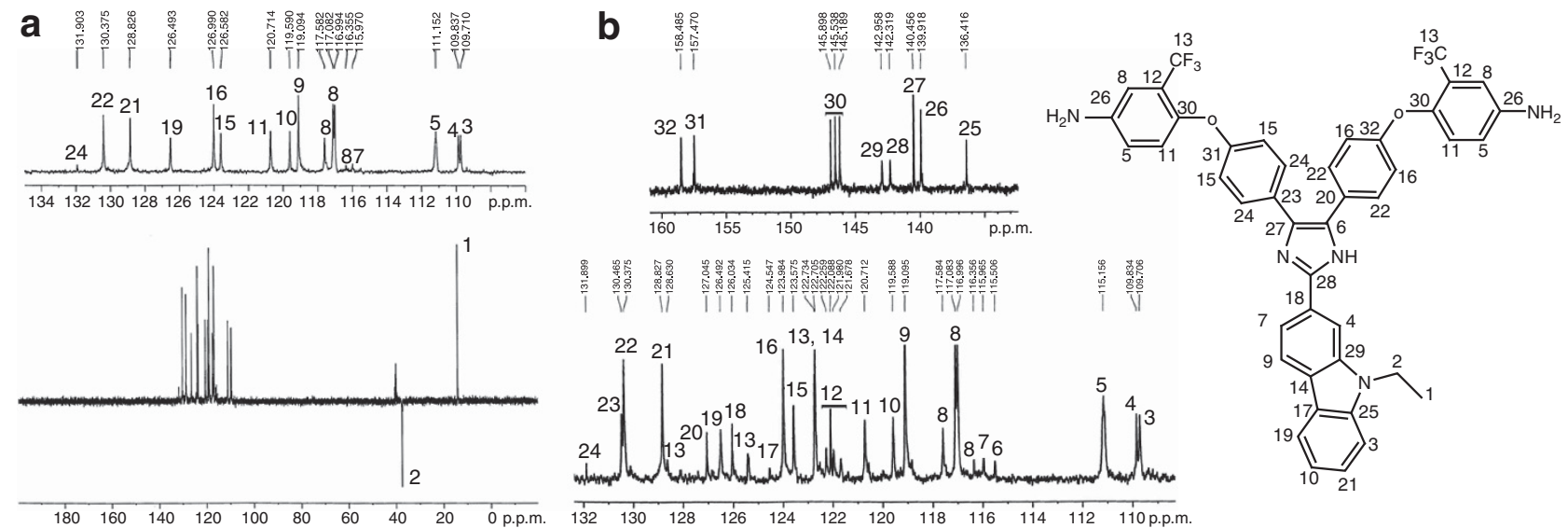

Figure 2 Carbon-13 nuclear magnetic resonance $\left({ }^{13} \mathrm{C}-\mathrm{NMR}\right)$ spectra of diamine (4) in dimethyl sulfoxide (DMSO)- $d_{6}$ : (a) Distortionless Enhancement by Polarization Transfer (DEPT) and (b) normal.

${ }^{13} \mathrm{C}-\mathrm{NMR}$ spectroscopy. The FT-IR spectrum of Compound 3 showed absorption bands at 1546 and $1349 \mathrm{~cm}^{-1}$ because of symmetric and asymmetric $-\mathrm{NO}_{2}$ stretching vibrations. After reduction, absorption peaks related to $\mathrm{NO}_{2}$ groups disappeared and new bands were observed at 3478 and $3373 \mathrm{~cm}^{-1}$ because of $\mathrm{N}-\mathrm{H}$ stretching. The ${ }^{1} \mathrm{H}-\mathrm{NMR}$ spectrum of Compound $\mathbf{4}$ in Figure 1 and the assigned protons reported in the experimental section confirmed that the nitro groups were completely transformed into amine groups by the high field shift of the aromatic protons and by the characteristic resonance of two different protons of two amine groups at 5.47 and 5.52 p.p.m.

The ${ }^{13} \mathrm{C}$-NMR spectrum of diamine 4 in Figure 2 showed 32 different carbon atoms for the aromatic segment and heterocyclic ring. The chemical shift in the upfield region (14.23 and 37.56 p.p.m.) is ascribed to the resonance of the aliphatic methyl group. Also, there are four quartet peaks because of the heteronuclear ${ }^{13} \mathrm{C}-{ }^{19} \mathrm{~F}$ coupling. The large quartet centered at about 123 p.p.m. is due to the $-\mathrm{CF}_{3}$ carbons. The one-bond C-F coupling constant in this case is about $270 \mathrm{~Hz}$. The $\mathrm{CF}_{3}$-attached carbon also shows a clear quartet centered at about 122 p.p.m. with a smaller coupling constant of about $32 \mathrm{~Hz}$ because of two-bond C-F coupling. These quartet signals corroborate the presence of the $\mathrm{CF}_{3}$ group in these compounds. Thus, all the spectroscopic data obtained by ${ }^{13} \mathrm{C}-\mathrm{NMR}$ and DEPT techniques were in good agreement with the expected chemical structures.

\section{Polymer synthesis and characterization}

As an extension of studies on the application of ILs in polycondensation, we wish to report a simple and efficient method for the polymerization of a new diamine with several readily accessible dicarboxylic acids in imidazolium-based ILs. The reaction proceeded efficiently with the combination of ILs and the activating agent TPP, enabling PA synthesis by direct polycondensation of dicarboxylic acids and diamines without using $\mathrm{NMP}, \mathrm{CaCl}_{2}$ (or $\mathrm{LiCl}$ ) or Py, which are necessary when using traditional organic solvents. This investigation used room temperature ILs, predominantly those based on substituted imidazolium cations, which can be prepared simply from the commercially available starting materials $\mathrm{N}$-trimethylsilylimidazole and alkyl halides. ${ }^{35,10}$ Thus, the different symmetrical 1,3dialkylimidazolium ILs bearing $\mathrm{Br}^{-}, \mathrm{PF}^{-}$and $\mathrm{BF}_{6}^{-}$anions shown in Table 1 were prepared and used as polycondensation agents. These ILs are soluble in polar solvents, such as water and methanol, allowing for the complete isolation of the obtained polymers.

To determine the effect of the nature of ILs on the yield and viscosity of the polymer, the synthesis of aromatic PAEI1 and

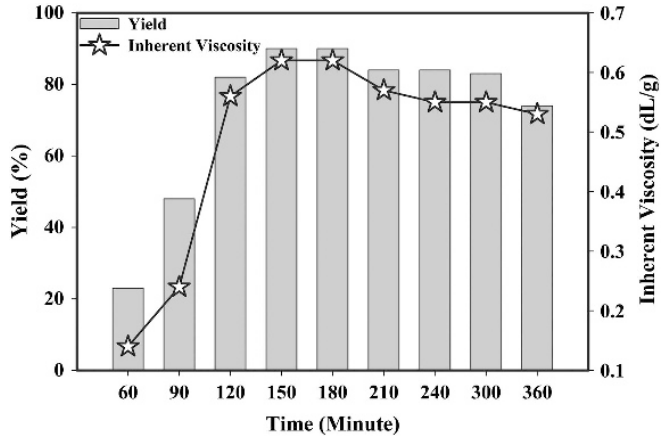

Figure 3 Optimal conditions for the synthesis of poly(amide-ether-imidazole) (PAEI)1 in ionic liquid (IL).

aliphatic PAEI5 were carried out in different imidazolium-type ILs at a constant reaction temperature. Table 1 compares the yields and viscosities of these two representative polymers in different ILs. The yield of aliphatic PAEI5 is higher, whereas the viscosity is somewhat lower compared with the aromatic PAEI1. IL needs to be a thermally stable liquid near the process temperature and to be a good solvent either for initial monomers or for the resulting polymers. These ILs were all very viscous liquids at room temperature. Therefore, the polycondensation temperature $\left(110^{\circ} \mathrm{C}\right)$ was determined by the viscosity of the ILs and the solubility of the diamine 4. Although the representative PAEI1 and PAEI5 were soluble in all ILs, as the alkyl chain length in the ILs increased, the yield and viscosity decreased. This can be explained by the decrease in the polarity of the IL, resulting in a decreased mobility of polymer chains in ILs with longer alkyl chains. The highest yield and viscosity of the polymers PAEI1 and PAEI5 were obtained when $\left[1,3-(\operatorname{Pr})_{2} \mathrm{im}\right] \mathrm{Br}$ was used as the reaction medium, and this IL was also selected for the synthesis of other PAEIs (Table 1). The optimum polycondensation time was determined for the preparation of PAEI1 in the selected IL and at the selected temperature by measuring the yield and viscosity of the polymer at different times. These results are shown in Figure 3. The best results were achieved in ILs with $\mathrm{Br}^{-}$as the anion. As shown by the data in Table 2, using aliphatic acids as the initial materials resulted in higher polymer yields. All of the PAEIs (1-6) were prepared in two different reaction conditions: direct polycondensation reactions using NMP/Py/LiCl/TPP and reactions with a combination of $\left[1,3-(\mathrm{Pr})_{2} \mathrm{im}\right] \mathrm{Br} / \mathrm{TPP}$. The results in Table 2 demonstrate the beneficial effects of using IL/TPP combinations in the synthesis of 
PAs, in addition to other useful properties, such as the non-volatility of ILs. Furthermore, removal of some chemicals (for example, NMP, $\mathrm{LiCl}$ and $\mathrm{Py}$ ) that are essential for conventional direct polycondensation and increasing the reaction time ( $12 \mathrm{vs} 2.5 \mathrm{~h}$ ) increases the cost of polymerization as well as the resulting environmental pollution.
The PAEIs were obtained as light brown powders with good yields, 85-95\% after extraction with refluxing methanol for $24 \mathrm{~h}$ to remove low fraction oligomers, and their inherent viscosities were in the range of $0.34-0.62 \mathrm{dlg}^{-1}$, indicating intermediate molecular weights. The structures of the polymers were identified by means of elemental

Table 2 Solubility of synthesized PAEI1-6

Solvent

\begin{tabular}{|c|c|c|c|c|c|c|c|c|c|c|c|}
\hline Code & Yield (\%) & $\eta_{i n h}\left(d / g^{-1}\right)^{a}$ & $D M A C$ & $D M F$ & NMP & DMSO & Py & THF & $\mathrm{CH}_{2} \mathrm{Cl}_{2}$ & $\mathrm{CH}_{3} \mathrm{CN}$ & m-Cresol \\
\hline PAEI1 & 90 & 0.62 & ++ & ++ & ++ & ++ & + & \pm & - & - & + \\
\hline PAEI2 & 87 & 0.51 & ++ & ++ & ++ & ++ & + & \pm & - & - & + \\
\hline PAEI3 & 85 & 0.39 & ++ & ++ & ++ & ++ & + & \pm & - & - & + \\
\hline PAEI4 & 91 & 0.53 & ++ & ++ & ++ & ++ & + & \pm & - & - & + \\
\hline PAEI5 & 92 & 0.37 & ++ & ++ & ++ & ++ & ++ & + & - & - & ++ \\
\hline PAEI6 & 95 & 0.34 & ++ & ++ & ++ & ++ & ++ & + & - & - & ++ \\
\hline PAEIla & 84 & 0.60 & ++ & ++ & ++ & ++ & + & \pm & - & - & + \\
\hline PAEI2a & 88 & 0.49 & ++ & ++ & ++ & ++ & + & \pm & - & - & + \\
\hline PAEI3a & 84 & 0.40 & ++ & ++ & ++ & ++ & + & \pm & - & - & + \\
\hline PAEI4a & 82 & 0.56 & ++ & ++ & ++ & ++ & + & \pm & - & - & + \\
\hline PAEI5a & 86 & 0.31 & ++ & ++ & ++ & ++ & ++ & + & - & - & ++ \\
\hline PAEI6a & 81 & 0.26 & ++ & ++ & ++ & ++ & ++ & + & - & - & ++ \\
\hline
\end{tabular}

Abbreviations: DMAc, $N, N$-dimethylacetamide; DMF, $N, N$-dimethylformamide; DMSO, dimethyl sulfoxide; $\eta_{\text {inh, }}$ inherent viscosity; IL, ionic liquid; NMP, $N$-methyl-2-pyrrolidone; PAEI, poly(amideether-imidazole); Py, pyridine; THF, tetrahydrofuran; TPP, triphenyl phosphite.

++ , Soluble at room temperature.

+ , Soluble on heating at $60^{\circ} \mathrm{C}$

\pm , Partially soluble on heating at $60^{\circ} \mathrm{C}$.

-, Insoluble on heating at $60^{\circ} \mathrm{C}$

PAEI1-6 and PAEI1a-6a were synthesized in IL/TPP and NMP/TPP/Py/LiCl media, respectively.

a Measured at a polymer concentration of $0.5 \mathrm{gdl}^{-1}$ in NMP at $25^{\circ} \mathrm{C}$.

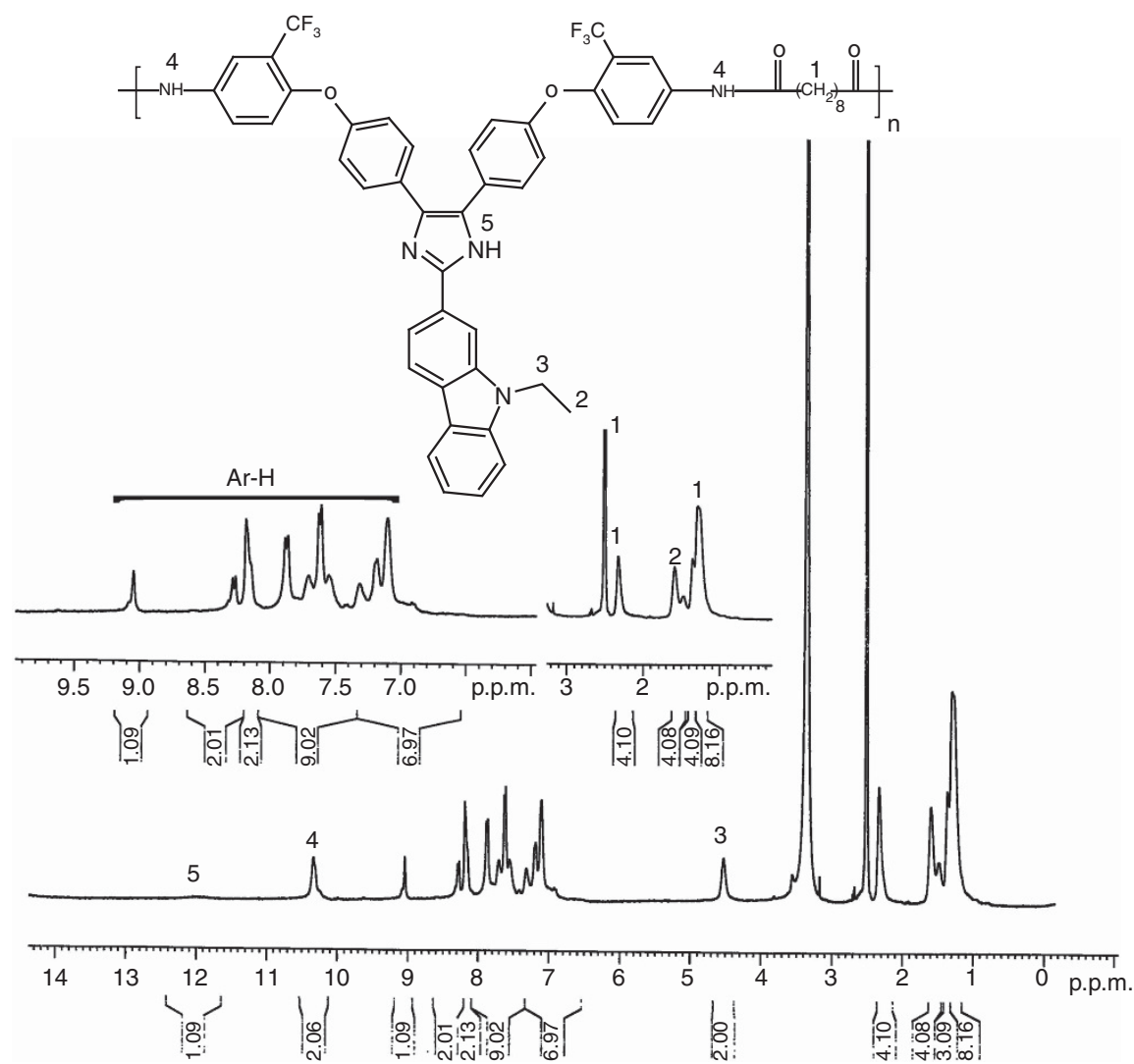

Figure 4 Proton nuclear magnetic resonance spectroscopy $\left({ }^{1} \mathrm{H}-\mathrm{NMR}\right)$ spectrum of poly(amide-ether-imidazole) (PAEI) 6 in dimethyl sulfoxide (DMSO)- $d_{6}$. 
analysis, FT-IR and ${ }^{1} \mathrm{H}-\mathrm{NMR}$ spectroscopy. The elemental analysis values generally agreed with the calculated values for the proposed polymer structures. FT-IR spectra of these PAEIs showed characteristic absorption peaks at $3300 \mathrm{~cm}^{-1}$ and at $1670 \mathrm{~cm}^{-1}$ related to the $\mathrm{N}-\mathrm{H}$ and $\mathrm{C}=\mathrm{O}$ groups of amide linkages. Figure 4 shows a typical ${ }^{1} \mathrm{H}-\mathrm{NMR}$ spectrum of the PAEI6 in DMSO- $d_{6}$; all the peaks have been assigned to the hydrogen atoms of the repeating unit in this polymer. There are two types of $\mathrm{N}-\mathrm{H}$ protons in the backbones of these polymers, $\mathrm{N}-\mathrm{H}$ protons of amide groups in the region of 10.34 p.p.m. and the $\mathrm{N}-\mathrm{H}$ proton of the imidazole ring, which appeared as a single peak at 11.96 p.p.m. The signals related to the aromatic and aliphatic protons in the PAEI6 structure appeared in the ranges of 6.91-9.13 and $1.29-4.56$ p.p.m., respectively.

\section{Wide-angle X-ray diffraction and solubility of PAEIs}

The crystallinity of these polymers was evaluated by wide-angle X-ray diffraction. Figure 5 shows the X-ray diffractograms of three polymers, PAEI1-PAEI3-PAEI6. All the polymers showed completely amorphous patterns. This observation is reasonable because the presence of bulky pendants and unsymmetrical ether linkages in the polymer chain decreased the intermolecular forces between the chains, leading to a disturbance in the tight structure and indicating that the polymers were non-crystalline.

The solubilities of these PAEIs were determined at a concentration of $5 \%(\mathrm{wv})$ in a number of solvents, and the results are reported in Table 2 . All these polymers exhibited good solubility in polar aprotic solvents such as NMP, N,N-dimethylacetamide, $\mathrm{N}, \mathrm{N}$-dimethylformamide and DMSO, and the aliphatic PAs of PAEI5 and PAEI6 were even soluble in less polar solvents like Py and $m$-cresol at room temperature. In general, these polymers exhibited better solubility than common aromatic PAs, likely due to the introduction of bulky and polarized $\left(\mathrm{CF}_{3}\right.$, substituted imidazole and carbazole $)$ groups and

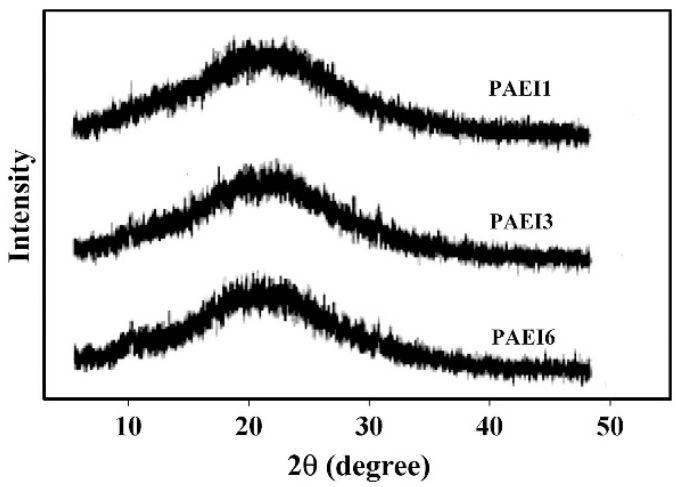

Figure 5 X-ray diffraction patterns of poly(amide-ether-imidazole) (PAEI)1, PAEI3 and PAEI6.

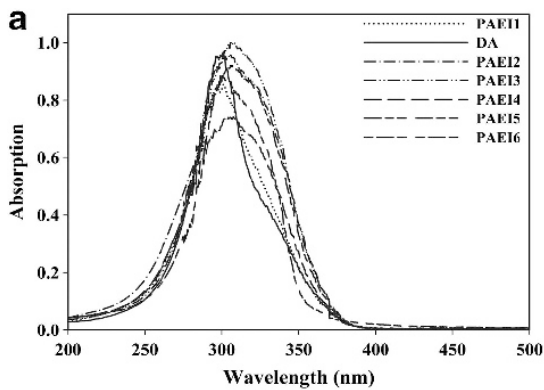

unsymmetrical linkages (ether) in the polymer backbones. This can be explained by the presence of bulky side groups such as substituted carbazole rings leading to chain separation, thus decreasing the interchain interactions between amide groups and allowing for better diffusion of solvent molecules into the chains to interact with the polar groups of the polymer backbones. Despite the fact that these polymers contain many bulky backbone groups such as phenyl groups, their solubilities are similar to those of previously reported PAs. ${ }^{37-40}$ In addition, the solubility of these polymers vary depending on the dicarboxylic acid used. In general, the aliphatic PAs PAEI5 and PAEI6 dissolved faster and exhibited better solubility in less polar solvents compared with the aromatic polymers (PAEI1-4).

Ultraviolet-visible absorption and fluorescence characteristics The ultraviolet-visible spectra of dilute NMP solutions of the diamine $\left(2 \times 10^{-5} \mathrm{M}\right)$ and the corresponding PAEIs $\left(0.2 \mathrm{~g} \mathrm{dl}^{-1}\right)$ are shown in Figure $6 \mathrm{a}$. The diamine and the polymers exhibited strong absorption at $300 \mathrm{~nm}$, which was assigned to a $\pi-\pi^{*}$ transition resulting from the conjugation of aromatic and heterocyclic rings. The optical properties of these PAs could also be elucidated from the cutoff wavelengths observed in the ultraviolet-visible spectra, listed in Table 3. The cutoff wavelengths of these PAs were up to $370 \mathrm{~nm}$, and the transmittance in the visible region (above $400 \mathrm{~nm}$ ) was over 100\%. The diamine showed strong blue fluorescent light, and when excited at $265 \mathrm{~nm}$ in a $2 \times 10^{-5} \mathrm{M}$ NMP solution, its maximum emission $\left(\lambda_{\max (\mathrm{em})}\right)$ was observed at $412 \mathrm{~nm}$. The fluorescence spectra of the PAEIs at $0.2 \mathrm{~g} \mathrm{dl}^{-1}$ in NMP exhibited emission between 400 and $600 \mathrm{~nm}$, with maxima around 440 and $500 \mathrm{~nm}$ for the aliphatic and aromatic PAEIs, respectively.

To measure the photoluminescence quantum yields $\left(\Phi_{\mathrm{f}}\right)$, dilute polymer solutions $\left(0.2 \mathrm{~g} \mathrm{dl}^{-1}\right)$ were prepared in NMP. A $0.1 \mathrm{~N}$

Table 3 Optical properties data of PAEI1-6

\begin{tabular}{lccc}
\hline Polymer & $\lambda_{a b s}(n m)$ & $\lambda_{e m}(n m)$ & $\Phi_{f}^{a}(\%)$ \\
\hline PAEI1 & 308 & 484 & 0.12 \\
PAEI2 & 307 & 474 & 0.11 \\
PAEI3 & 305 & 471 & 0.10 \\
PAEI4 & 305 & 461 & 0.09 \\
PAEI5 & 301 & 444 & 0.21 \\
PAEI6 & 301 & 437 & 0.29 \\
\hline
\end{tabular}

Abbreviations: NMP, $\mathrm{N}$-methyl-2-pyrrolidone; $\Phi_{f}$, photoluminescence quantum yields; PAEI, poly(amide-ether-imidazole).

Polymer concentration of $0.20 \mathrm{~g} \mathrm{dl}^{-1}$ in NMP.

aFluorescence quantum yield relative to $10^{-5} \mathrm{M}$ quinine sulfate in $1 \mathrm{~N} \mathrm{H}_{2} \mathrm{SO}_{4}$ (aq.) $\left(\Phi_{\mathrm{f}}=0.55\right)$ as a standard.

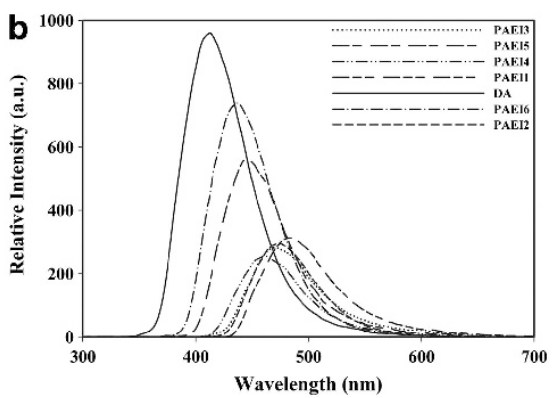

Figure 6 (a) Ultraviolet-visible (UV-vis) absorption and (b) fluorescence emission spectra of diamine (4) and poly(amide-ether-imidazole) (PAEI) 1-6. 
solution of quinine in $\mathrm{H}_{2} \mathrm{SO}_{4}\left(\Phi_{\mathrm{f}}=0.53\right)$ was used as a standard. ${ }^{41}$ The emission spectra of the diamine and PAEIs are shown in Figure $6 \mathrm{~b}$. The $\Phi_{\mathrm{f}}$ values were $35 \%$ for the diamine, $21-29 \%$ for the aliphatic PAEIs and 9-12\% for the aromatic PAEIs. The blue shifts and higher fluorescence quantum yields of the aliphatic PAs compared with the aromatic PAs may have been due to the reduced conjugation and the reduced capability of the aliphatic diacids to form charge-transfer complexes with the electron-donating diamine moiety compared with the stronger electron-accepting aromatic diacids. ${ }^{42}$ Because of their lower charge-transfer capacity, PAEI5 and PAEI6 exhibited a light color and high optical transparency. Intermolecular interactions between the carbazole and triarylimidazole moieties in the polymer backbone were negligible, presumably because both chromophores have similar absorption and emission properties. Polymer chains containing excited species may become entangled, leading to intersystem crossing to some extent, but the concrete reason for this result is unclear.

\section{Thermal properties}

DSC and TGA were used to evaluate the thermal properties of the polymers. DSC was performed at a heating rate of $10{ }^{\circ} \mathrm{C} \mathrm{min}^{-1}$ in a nitrogen atmosphere, and the resulting curves are shown in Figure 7. Quenching from $350{ }^{\circ} \mathrm{C}$ to room temperature yielded mainly amorphous samples without an exothermic peak related to crystallization, thus making the $T_{\mathrm{g}} \mathrm{s}$ of these polymers easily observed in the second DSC scans. The second DSC curves again did not display endothermic peaks up to $350^{\circ} \mathrm{C}$ because of the amorphous nature of the polymers. Among these polymers, PAEI1 and PAEI4 showed the highest $T_{\mathrm{g}}$ values because of the symmetrical structure of the remaining dicarboxylic acids in the polymer chain and the presence of more ordered segments that inhibited the molecular motion. The methylene units between the amide groups in PAEI5 and PAEI6 facilitated bond rotation and reduced $T_{\mathrm{g}}$ values. As a general rule, the incorporation of bulky and rigid units along a polymer backbone restrict the free rotation of the macromolecular chains and increase $T_{\mathrm{g}}$ values, but the presence of flexible ether linkages reduces the rigidity of the backbone to some extent, leading to a balance between these two opposing properties.

The thermal stability of these polymers was evaluated by TGA in $\mathrm{N}_{2}$ and $\mathrm{O}_{2}$ atmospheres, and the resulting curves are shown in Figure 8. The TGA data presented in Table 4 show that the temperatures of $10 \%$ weight loss were in the range of $421-521{ }^{\circ} \mathrm{C}$ and $388-492{ }^{\circ} \mathrm{C}$ in $\mathrm{N}_{2}$ and $\mathrm{O}_{2}$ atmospheres, respectively. All of these polymers exhibited good thermal stability with insignificant weight loss up to $388^{\circ} \mathrm{C}$ in air. The residual weight retention at $800^{\circ} \mathrm{C}$ for the PAEIs ranged from $33-72 \%$ in $\mathrm{N}_{2}$.

Char yield can be used to evaluate the limiting oxygen index (LOI) of the polymers in accordance with the Van Krevelen and Hoftyzer equation: ${ }^{43} \mathrm{LOI}=17.5+0.4 \mathrm{CR}$, where $\mathrm{CR}=$ char yield. The LOI values for all the polymers were calculated based on their char yields at $800{ }^{\circ} \mathrm{C}$. According to Table 4 , the aromatic PAEIs have better thermal stabilities and higher LOIs as compared with the aliphatic PAEIs. This result is likely related to the rigid structure of aromatic diacids compared with the flexible structure of aliphatic diacids. PAEI4 and PAEI6 have the highest and lowest thermal stabilities, respectively, because of the presence of rigid phenyl and flexible aliphatic units in their backbones. Therefore, these polymers possess excellent thermal stability because of their aromaticity, the strong electron negativity of the $\mathrm{F}$ atom and the high polarity of the $\mathrm{CF}_{3}$ group due to the high $\mathrm{C}-\mathrm{F}$ bond strength. ${ }^{44}$

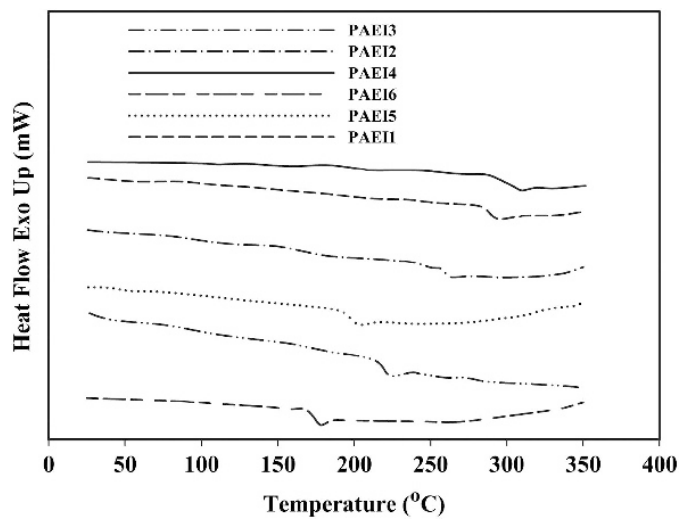

Figure 7 Differential scanning calorimetry (DSC) curves of poly(amide-etherimidazole) (PAEI) 1-6 under $\mathrm{N}_{2}$ at a heating rate of $10^{\circ} \mathrm{C} \mathrm{min}^{-1}$.

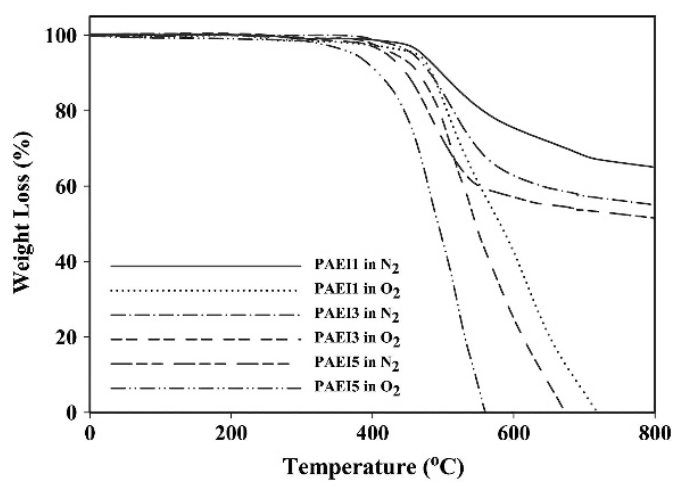

Figure 8 Thermogravimetric analysis (TGA) curves of poly(amide-etherimidazole) (PAEI)1, PAEI3 and PAEI5 under $\mathrm{N}_{2}$ and $\mathrm{O}_{2}$ at a heating rate of $10{ }^{\circ} \mathrm{Cmin}^{-1}$.

Table 4 Thermal properties of PAEI1-6

\begin{tabular}{lccccc}
\hline Polymer & $\mathrm{T}_{g}\left({ }^{\circ} \mathrm{C}\right)^{\mathrm{a}}$ & $\mathrm{T}_{10}\left({ }^{\circ} \mathrm{C}\right)^{\mathrm{b}}$ & $\mathrm{T}_{10}\left({ }^{\circ} \mathrm{C}\right)^{\mathrm{c}}$ & Char yield $^{\mathrm{d}}$ & LOI (\%) $^{\mathrm{e}}$ \\
\hline PAEI1 & 288 & 497 & 480 & 65 & 44 \\
PAEI2 & 260 & 488 & 473 & 61 & 42 \\
PAEI3 & 218 & 482 & 460 & 55 & 40 \\
PAEI4 & 300 & 521 & 492 & 72 & 46 \\
PAEI5 & 197 & 448 & 413 & 51 & 38 \\
PAEI6 & 173 & 436 & 405 & 48 & 37 \\
PAEI1a & 286 & 464 & 469 & 54 & 39 \\
PAEI2a & 260 & 469 & 466 & 50 & 38 \\
PAEI3a & 219 & 477 & 441 & 41 & 34 \\
PAEI4a & 303 & 483 & 489 & 68 & 45 \\
PAEI5a & 207 & 440 & 402 & 41 & 34 \\
PAEI6a & 162 & 421 & 388 & 33 & 31
\end{tabular}

Abbreviations: IL, ionic liquid; LOI, limiting oxygen index; NMP, $N$-methyl-2-pyrrolidone; PAEI, poly(amide-ether-imidazole); Py, pyridine; $T_{g}$, glass transition temperature; TGA,

thermogravimetric analysis; TPP, triphenyl phosphate.

PAEI1-6 and PAEI1a-6a were synthesized in IL/TPP and NMP/TPP/Py/LiCl media, respectively.

${ }^{a} T_{\mathrm{g}}$ was recorded at a heating rate of $20^{\circ} \mathrm{C} \mathrm{min}^{-1}$ in $\mathrm{N}_{2}$.

bTemperature at which $10 \%$ weight loss was recorded by TGA in $\mathrm{N}_{2}$.

CTemperature at which $10 \%$ weight loss was recorded by TGA in $\mathrm{O}_{2}$.

dPercentage weight of material left undecomposed after TGA analysis at a temperature of $800{ }^{\circ} \mathrm{C}$ in $\mathrm{N}_{2}$

eLOI percent evaluating at char yield at $650^{\circ} \mathrm{C}$. 


\section{CONCLUSIONS}

This study reports the possibility of using imidazolium-based ILs in a simple and efficient approach for the synthesis of photoactive and organosoluble high-performance PAs. For comparison purposes, a series of PAEIs were prepared from a new diamine and various dicarboxylic acids via direct polycondensation using NMP/TPP/Py/ $\mathrm{LiCl}$ and a combination of IL/TPP without NMP/Py/LiCl. In general, the results demonstrated the beneficial effects of using IL/TPP media in the synthesis of PAs, such as good yields, moderate viscosity and shorter reaction time, without the need for the removal of chemicals (for example, NMP, $\mathrm{LiCl}$ and $\mathrm{Py}$ ) and without using volatile chemicals. These PAs have different functional groups, such as ether linkages, bulky groups such as $\mathrm{CF}_{3}$ and substituted imidazole and carbazole groups, along their backbones that give rise to restricted segmental mobility, resulting in a high $T_{\mathrm{g}}$ (up to $300^{\circ} \mathrm{C}$ ) and an enhancement in solubility in many organic solvents. These polymers exhibit high thermal stability ( $T_{10}$ up to $492^{\circ} \mathrm{C}$ in $\mathrm{O}_{2}$ ) because of their aromatic structure and the presence of strong $\mathrm{C}-\mathrm{F}$ bonds, and these polymers also emit fluorescent light at $\lambda_{\text {e.max }}=437-484 \mathrm{~nm}$ with $\Phi_{\mathrm{f}}$ up to $29 \%$.

\section{CONFLICT OF INTEREST}

The authors declare no conflict of interset.

\section{ACKNOWLEDGEMENTS}

We thank the Research Affairs Division of the University of Mazandaran (UMZ), Babolsar (Iran), for partial financial support.

1 Wasserscheid, P. \& Welton, T. Ionic Liquids in Synthesis (Wiley-VCH, KGaA, Weinheim, 2002)

2 Lu, J., Yan, F. \& Texter, J. Advanced applications of ionic liquids in polymer science. Prog. Polym. Sci. 34, 431-448 (2009).

3 Kubisa, P. Application of ionic liquids as solvents for polymerization processes. Prog. Polym. Sci. 29, 3-12 (2004)

4 Welton, T. Room-temperature ionic liquids. Solvents for synthesis and catalysis. Chem. Rev. 99, 2071-2084 (1999).

5 Lozinskaya, E. I., Shaplov, A. S. \& Vygodskii, Y. S. Direct polycondensation in ionic liquids. Eur. Polym. J. 40, 2065-2075 (2004).

6 Kubisa, P. Ionic liquids in the synthesis and modification of polymers. J. Polym. Sci. Part A 43, 4675-4683 (2005)

7 Lozinskaya, E. I., Shaplov, A. S., Kotseruba, M. V., Komarova, L. I., Lyssenko, K. A., Antipin, M. Y., Golovanov, D. G. \& Vygodskii, Y. S. "One-pot" synthesis of aromatic poly(1,3,4-oxadiazole)s in novel solvents-ionic liquids. J. Polym. Sci. Part A 44, 380-394 (2006)

8 Yoneyama, M. Direct polycondensation of aromatic tetracarboxylic acids with aromatic diamines in ionic liquids. High Perform. Polymer (Guildf) 18, 817-823 (2006).

9 Paraknowitsch, J. P., Thomas, A. \& Antonietti, M. A detailed view on the polyconden sation of ionic liquid monomers towards nitrogen doped carbon materials. J. Mater. Chem. 20, 6746-6758 (2010).

10 Vygodskii, Y. S., Lozinskaya, E. I., Shaplov, A. S., Lyssenko, K. A., Antipin, M. Y. \& Urman, Y. G. Implementation of ionic liquids as activating media for polycondensation processes. Polym. J. 45, 5031-5045 (2004).

11 Cassidy, P. E. Thermally Stable Polymer Chapter 4 (Dekker, New York, 1980).

12 García, J. M., García, F. C., Serna, F. \& de la Peña, J. L. High-performance aromatic polyamides. Prog. Polym. Sci. 5, 623-686 (2010)

13 Hearle, J. W. High-Performance Fibres (Woodhead Publishing, Cambridge, UK, 2001).

14 Gaudiana, R. A., Minns, R. A., Sinta, R., Weeks, N. \& Rogers, H. G. Amorphous rigid rod polymers. Prog. Polym. Sci. 14, 47-89 (1989).

15 Hsiao, S. H. \& Lin, K. H. Soluble aromatic polyamides bearing asymmetrical diaryl ether groups. Polymer (Guildf) 45, 7877-7885 (2004).

16 Kricheldorf, H. R., Bohme, S. \& Schwarz, G. Macrocycles. 17. The role of cyclization in kinetically controlled polycondensations. 2. Polyamides. Macromolecules 34 8879-8885 (2001).

17 Liou, G. S., Hsiao, S. H., Ishida, M., Kakimoto, M. \& Imai, Y. Synthesis and characterization of novel soluble triphenylamine-containing aromatic polyamides based on $N, N^{\prime}$-bis(4-aminophenyl)- $N, N^{\prime}$-diphenyl-1,4-phenylenediamine. J. Polym. Sci. Part A 40, 2810-2818 (2002)

18 Liu, Y. -L., Li, S. -H., Lee, H. -C. \& Hsu, K. -Y. Selective reactivity of aromatic amines toward 5-maleimidoisophthalic acid for preparation of polyamides bearing $\mathrm{N}$-phenylmaleimide moieties. React. Funct. Polym. 66, 924-930 (2006).
19 Mallakpour, S. \& Taghavi, M. Kinetics and thermal degradation study of optically active and thermally stable aromatic polyamides with flame-retardancy properties. Polym. J. 41, 308-318 (2009).

20 Ghaemy, M., Amini Nasab, S. M. \& Alizadeh, R. Synthesis and characterization of new soluble polyamides from an unsymmetrical diamine bearing a bulky triaryl pyridine pendent group. J. Appl. Polym. Sci. 116, 3725-3731 (2010).

21 Ghaemy, M. \& Alizadeh, R. Synthesis of soluble and thermally stable polyimides from unsymmetrical diamine containing 2, 4, 5-triaryl imidazole pendent group. Eur. Polym. J. 45, 1681-1688 (2009).

22 Ghaemy, M. \& Amini Nasab, S. M. Synthesis and characterization of organo-soluble polyamides containing triaryl imidazole pendant and ether linkage moieties: thermal, photophysical, and chemiluminescent properties. Polym. Adv. Technol. 22 2311-2318 (2011).

23 Amini Nasab, S. M. \& Ghaemy, M. Synthesis and characterization of new polyamides and polyimides containing dioxypyrimidine moiety in the main chain with bulky imidazole pendent group: solubility, thermal and photophysical properties. J. Polym. Res. 18, 1575-1586 (2011).

24 Ghaemy, M. \& Amini Nasab, S. M. Synthesis and identification of organosoluble polyamides bearing a triaryl imidazole pendent: thermal, photophysical, chemiluminescent, and electrochemical characterization with a modified carbon nanotube electrode. React. Funct. Polym. 70, 306-313 (2010).

25 Ghaemy, M., Alizadeh, R. \& Behmadi, H. Synthesis of soluble and thermally stable polyimide from new diamine bearing $\mathrm{N}$-[4-(9H-carbazol-9-yl)phenyl] formamide pendent group. Eur. Polym. J. 45, 3108-3115 (2009).

26 Ghaemy, M. \& Amini Nasab, S. M. Synthesis and identification of organosoluble polyimides: thermal, photophysical and chemiluminescence properties. Polym. J. 42, 648-656 (2010)

27 Ghaemy, M. \& Alizadeh, R. Synthesis, characterization and photophysical properties of organosoluble and thermally stable polyamides containing pendent $\mathrm{N}$-carbazole group. React. Funct. Polym. 71, 425-432 (2011).

28 Kim, H. C., Kim, J. S., Kim, K. S., Park, H. K., Baek, S. \& Ree, M. Synthesis and characterization of new, soluble polyazomethines bearing fluorene and carbazole units in the backbone and solubility-improving moieties in the side group. J. Polym. Sci. Part A 42, 825-834 (2004)

29 Grigalevicius, S., Grazulevicius, J. V., Gaidelis, V. \& Jankauskas, V. Synthesis and properties of poly(3,9-carbazole) and low-molar-mass glass-forming carbazole compounds. Polymer (Guildf) 43, 2603-2608 (2002).

30 Grazulevicius, J. V., Strohriegl, P., Pielichowski, J. \& Pielichowski, K. Carbazolecontaining polymers: synthesis, properties and applications. Prog. Polym. Sci. 28, 1297-1353 (2003)

31 Angiolini, L., Giorgini, L., Li, H., Golemme, A., Mauriello, F. \& Termine, R. Synthesis, characterization and photoconductive properties of optically active methacrylic polymers bearing side-chain 9-phenylcarbazole moieties. Polymer (Guildf) 51, 368-377 (2010).

32 Liou, G. S., Hsiao, S. H., Huang N. K. \& Yang Y. L. Synthesis, photophysical, and electrochromic characterization of wholly aromatic polyamide blue-light-emitting materials. Macromolecules 39, 5337-5346 (2006)

33 Barghamadi, M., Ghaemy, M. \& Alizadeh, R. Non-isothermal cure kinetics of diglycidy ether of bisphenol-a with various aromatic diamines. Iran. Polym. J. 18, 431-443 (2009)

34 Liou, G. S., Chen, H. W. \& Yen, H. J. Synthesis and photoluminescent and electrochromic properties of aromatic poly(amine amide)s bearing pendent $\mathrm{N}$-carbazolylphenyl moieties. J. Polym. Sci. Part A 44, 4108-4121 (2006).

35 Vygodskii, Y. S., Lozinskaya, E. I. \& Shaplov, A. S. Ionic liquids as novel reaction media for the synthesis of condensation polymers. Macromol. Rapid Commun. 23, 676-680 (2002)

36 Chauveau, E., Marestin, C., Martin, V. \& Mercier, R. G. Microwave-assisted polymerzation process: a way to design new, high molecular weight poly(arylimidazole)s. Polymer (Guildf) 49, 5209-5214 (2008).

37 Hsiao, S.-H. \& Chang, Y.-H. New soluble aromatic polyamides containing ether linkages and laterally attached p-terphenyls. Eur. Polym. J. 40, 1749-1757 (2004).

38 Ge, Z., Yang, S., Tao, Z., Liu, J. \& Fan, L. Synthesis and characterization of novel soluble fluorinated aromatic polyamides derived from fluorinated isophthaloyl dichlorides and aromatic diamines. Polymer (Guildf) 45, 3627-3635 (2004).

39 Hsiao, S. H., Chen, C. W. \& Liou, G. S. Novel aromatic polyamides bearing pendent diphenylamino or carbazolyl groups. J. Polym. Sci. Part A 42, 3302-3313 (2004)

40 Sheng, S. -R., Pei, X. -L., Huang, Z. -Z., Liu, X. -L. \& Song, C. -S. Nove soluble fluorinated aromatic polyamides derived from 2-(4-trifluoromethylphenoxy)terephthaloyl chloride with various aromatic diamines. Eur. Polym. J. 45, 230-236 (2009)

41 Feng, K., Hsub, F. L., Van DerVeer, D., Bota, K. \& Xiu, R. Tuning fluorescence properties of imidazole derivatives with thiophene and thiazole. J. Photochem. Photobiol. A 165, 223-228 (2004).

42 Liou, G. S. \& Chang, C. W. Highly stable anodic electrochromic aromatic polyamidescontaining $N, N, N, N$-tetraphenyl-p-phenylenediamine moieties: synthesis, electrochemical, and electrochromic properties. Macromolecules 41, 1667-1674 (2008)

43 Van Krevelen, D. W. \& Hoftyzer, P. J. Properties of Polymers 3rd edn (Elsevier Scientific Publishing, Amsterdam, 1976).

44 Yin, D., Li, Y., Shao, Y., Zhao, X., Yang, S. \& Fan, L. Synthesis and characterization of soluble polyimides based on trifluoromethylated aromatic dianhydride and substitutional diaminetriphenylmethanes. J. Fluorine Chem. 126, 819-823 (2005). 